Revista de la red interuniversitaria de estudios sobre las literaturas rioplatenses contemporáneas en Francia

$6 \mid 2011$

Juan José Saer. archivos, memoria, critica

\title{
Incipit vita nova
}

\section{Martín Arias}

\section{OpenEdition}

\section{Journals}

\section{Edición electrónica}

URL: http://journals.openedition.org/lirico/196

DOI: $10.4000 /$ lirico. 196

ISSN: 2262-8339

Editor

Réseau interuniversitaire d'étude des littératures contemporaines du Río de la Plata

Edición impresa

Fecha de publicación: 1 diciembre 2011

Paginación: 215-219

ISBN: 2-9525448-5-9

ISSN: 2263-2158

Referencia electrónica

Martín Arias, «Incipit vita nova », Cuadernos LIRICO [En línea], 6 | 2011, Publicado el 01 julio 2012, consultado el 22 septiembre 2020. URL : http://journals.openedition.org/lirico/196 ; DOl : https:// doi.org/10.4000/lirico.196

\section{(2) $\odot \Theta \Theta$}

Cuadernos LIRICO está distribuido bajo una Licencia Creative Commons Atribución-NoComercialSinDerivar 4.0 Internacional. 


\section{Incipit vita nova}

La casa encontrada. Poesía reunida, 1979-2010

Roberto Raschella

Fondo de Cultura Económica, Buenos Aires, 2011

a casa encontrada reúne por primera vez los tres poemarios
publicados hasta el momento por Raschella -Malditos los
gallos (1979), Poemas del exterminio (1988) y Tímida hierba de agosto (2001)-, más uno inédito, fechado en 2010, que da su título al volumen. Guillermo Saavedra firma el prólogo, llamado "El sueño de un futuro inexacto".

Desde el comienzo, la lengua poética de Roberto Raschella se ampara en un discreto escenario mítico, el lugar de un relato que cuenta la peripecia de un origen. A la vez doméstico y transoceánico, ese escenario (presentado en una nota lingüístico-biográfica que cierra el primer libro) es una "casa de patio rojo" en la ciudad de Buenos Aires. Durante la infancia y la adolescencia, el poeta escuchó allí las conversaciones de sus padres calabreses con paisanos y amigos, diálogos cuyas palabras provenían ya del más diáfano italiano, ya de un dialecto confinado a un valle del extremo sur de la península, ya, por fin, del lunfardo practicado en el barrio porteño de Boedo hacia los años treinta y cuarenta (Raschella nació en septiembre de 1930, mientras el caudillo Yrigoyen era expelido por las tropas de Uriburu). De esas contaminaciones, o para decirlo con un verso de Malditos los gallos, de esas "entremezclas, pindáricos vuelos estremecidos", obtendrá el escritor buena parte de su vocabulario. Así leeremos en "Poema de la familia":

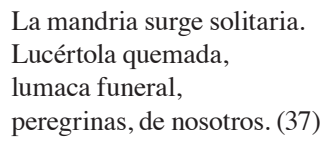

En la nota mencionada más arriba, consta que lucértola significa lagarto, y lumaca, caracol. Acaso podamos prescindir de esas indicaciones, pues no debería exagerarse el aspecto críptico de este idioma felizmente impuro de Raschella. Lo críptico es, en verdad, ocasional en su poesía, e incluso la novela Diálogos en los patios rojos (1994), donde las piezas léxicas obtenidas en la intimidad del idiolecto se incrustan en casi cada párrafo, los contenidos movimientos entre cadencias y sentidos les permiten a las frases mantenerse muy cerca, aunque más acá de un radical hermetismo. En líneas como: "Y me saludan... doverosas como flores 
apasidas"1, no es necesario conocer el significado exacto de los adjetivos italianos para participar de aquello que esta lengua da a leer. ¿Y qué da a leer, entonces, esta lengua en que "lo impuro regresa, a lo impuro"?

En su prólogo a una escandalosa novela de los años cincuenta, Jean Paulhan (quien, a través de su oposición entre la Retórica y el Terror en las letras, acaso figure entre las referencias literarias de La casa encontrada) ${ }^{2}$ observaba que "La Historia de $O$ viene de lejos. Al leerla, experimento en primer lugar ese sosiego, y como esos espacios que le deja a un relato el haber sido largamente llevado por su autor: el serle familiar". ${ }^{3}$ Es lo que encontramos en este libro: palabras largo tiempo sabidas, muchas veces pronunciadas, tan familiares para quien las escribe que su existencia en el verso no le pide a quien las lee nada sino un detenimiento de lectura, pues llegan a la página "como un pan de lentitud" (72). La lentitud, de hecho, la "amorosa lentitud", la "lenta posesión del aire / y de las flores" (276), parecería ser el verdadero don del poema raschelleano, como si la acción restringida que lleva a cabo la poesía tuviese lugar en los más extendidos transcursos del tiempo. Sólo ellos le permiten a quien escribe la cantidad de atención necesaria para advertir ciertos cambios, verificar ciertos movimientos, para notar, por ejemplo, que "pequeñas herejías bajan lejanas, / y los juglares más enloquecidos / provocan la lenta metamorfosis de las lenguas" (140). Así también la cita de La Odisea con que se abre el segundo de estos libros nos recuerda que Proteo, quien se transforma en todas las cosas, incluye vastas zonas de tiempo pues es un anciano. Y si hablamos de lentitud en lengua y literatura, conviene no olvidar que hubo otro poeta -Osvaldo Lamborghini-que escribió en la "lenta, crujiente fractura de las jergas y la lengua...". 4 Por cierto, que justamente Lamborghini, en un rapto de curiosa anglofilia, haya titulado uno de sus poemas "Raschella in the night", que haya sido él quien citara más de una vez un verso de Malditos los gallos, demuestra el error de creer que estamos hablando de algún escritor ignorado. Esa impresión falaz proviene de la capacidad de Raschella para mantenerse inactual (en el sentido nietzscheano de la palabra, vale decir, a una cierta distancia respecto del presente, la necesaria como para mirar de frente la propia

\footnotetext{
1 R. Raschella, Diálogos en los patios rojos, Buenos Aires, Paradiso, pp. 26-27.

2 "Pero hay algo constitucional / que no es retórico ni demostrativo, por eso muerto, por eso vivo." (La casa encontrada, p. 96); "La rabia y la violencia no son retóricas. / No las toques con nuestras palabras, no hagas / de ellas nuestros fetiches..." (Ibid., p. 125).

3 En P. Réage, Histoire d'O, Paris, Pauvert, 2009, p. 12.

4 O. Lamborghini, Novelas y cuentos, Barcelona, Del Serbal, 1988, p. 54.
} 
época) y de unos lapsos de publicación que se cuentan en décadas. Pero entretanto, sus actividades fueron numerosas.

En 1986, y como parte del consejo de redacción de la revista Innombrable, difundió un escrito de su ya citado lector, que había fallecido poco antes. La causa justa se llamaba esa obra, y se convertiría en una pieza clave de la literatura argentina de fines del siglo veinte. Previamente había colaborado con revistas como Cinema Nuovo, Cinecrítica, Tiempo de cine y Lyra, escrito guiones cinematográficos (adaptaciones de "La refalosa" de Ascasubi, Allá lejos y hace tiempo de Hudson y "El matadero" de Echeverría se cuentan entre sus proyectos) y traducido, entre otros, a Dante, Maquiavelo, D’Annunzio y Pasolini. Además de la novela ya citada, publicó otra, Si hubiéramos vivido aquí (1997), y junto a Mariano Fiszman, La historia que nunca les conté (2005). A eso se suman la militancia en el Partido Comunista y la melomanía.

Como haces de una misma compacidad, la poesía de Raschella liga todos esos aspectos en lo que podemos llamar una forma-de-vida. Tomamos prestada esta palabra al "Poema de la razón" (1970): "La estadística / se anotaba en pías alucinaciones, / y los testimonios amasaban un lenguaje / de luces. El arte era un término fungible, / jamás una forma de vida" (122); los guiones, por su parte, provienen de G. Agamben, quien con esa puntuación busca designar lo inseparable de una vida y su forma, su manera: un modo de vivir indiscernible del viviente. Es, por el contrario, la administración biopolítica (la estructura actual del poder) la que se funda en una división tenaz de una pura vida, por un lado, y por otro una forma de la que esa vida bien podría carecer. El poeta argentino recusa tal escisión y anuda vida y forma, tal como anuda, al español, el dialecto de Mammola, en Calabria.

Anuda. También podríamos decir: anota. Pues el ejercicio de observar y anotar ocupa un lugar crucial en el arte de Raschella: "Anota todos los movimientos: tus movimientos son trascendentes aun si se pierden o si están fijos / en sus círculos" (105); "Esto es lo observado. Sentarse y anotar..." (101). Recordemos que, en tanto práctica cotidiana, la anotación fue investigada por Barthes bajo las especies de nota, notula y notatio, y definida por el crítico como la captura de una esquirla, de una "viruta de presente" tal como ésta salta a la observación, a la consciencia. En ese registro obsesivo de lo real, los actos y los procesos de la vida ("movimientos" dice el poeta, con un término que habría que leer en su acepción musical) no son nunca simples hechos de una vida pura, desnuda, sino que poseen una forma, un léxico, un ritmo y una sintaxis, 
aunque más no sea una sintaxis ínfima o precaria, una "sintaxis avispal" como dice Raschella. Asimismo, de la anotación deriva la presencia, en algún poema, del cuaderno, soporte de una cura sui, de un cuidado de sí. ${ }^{5}$ Pues transcriptas como frases en los cuadernos, las observaciones van tramando el espacio posible de una forma de vida. Barthes dice: "Vivir, en el sentido más activo, el más espontáneo, el más sincero, y yo diría el más salvaje, es recibir las formas de la vida de frases que nos preexisten". 6 A Raschella, como ya se dijo, esas formas anteriores le llegan de una lengua trabajada por el tiempo y las herejías dialectales, luego aquilatada en las míticas conversaciones del patio rojo.

Pero además, la mención del cuaderno permite recordar que el poeta se desempeñó, durante treinta años, como maestro de educación elemental. Nada de pueril, sin embargo, en esas notas. Un poema fechado en los años argentinos del exterminio se abre con estos versos:

Cuadernos de vida se disipan,
terriblemente extendidos.
Son inocentes, como los muertos
en las zanjas abiertas todavía,
de pantalones azules y rabiosos,
de violeta, a veces rojos, siempre rojos.

Me atormentan, los cuadernos, los muertos. (147)

Es en relación con esas acechanzas de los cuadernos que podemos leer, por ejemplo, ciertas referencias al cine. Así estos versos lacónicos,

5 Raúl Antelo ha destacado el lugar de este dispositivo en la poesía latinoamericana: "Buena parte de la modernidad local interviene en la esfera pública con las estrategias precisas de inversión discursiva en que el cuaderno, instrumento ejemplar de sujeción, se transforma en espacio del devaneo y del devenir. Es así en los montajes de Norah Borges, hechos con el cuaderno con que su hermano designaría su retorno a la patria: Cuaderno San Martín. Es así con el Primeiro Caderno do aluno de poesia Oswald de Andrade [...]. Es así con los dos primeros libros de Oliverio Girondo, que responden a la estructura serial del cuaderno de viaje. [...] Un estudioso de esos cuadernos de apuntes, Michel Foucault, veía los hypomnêmata como técnica privilegiada de cura sui. Los cuadernos no nos revelan lo oculto sino que reúnen lo dicho y, por esa vía, reconstruyen lo ilegible de una subjetividad" ("Introducción" a O. Girondo, Obra Completa, Madrid, Archivos, 1999, p.xxviii). Foucault, en sus estudios sobre la estética de la existencia en la cultura greco-romana, dice que los hypomnêmata eran notas sobre cosas leídas, escuchadas o pensadas, acumuladas en cuadernos como una memoria material que luego podía ser reactivada por el sujeto en diferentes contextos: la lectura, la meditación, la charla consigo mismo o con otros, pero también la escritura (Dits et écrits IV, Paris, Gallimard, 1994, pp. 418-423).

6 R. Barthes, La préparation du roman, Paris, Seuil, 2003, p. 149. 
estos versos-notulae de Tímida hierba de agosto: "la cabeza, / la cabeza rapada de Falconetti" (211). No es un azar que figure aquí el nombre de la actriz francesa que fue Juana de Arco en el filme de Dreyer (1927), la misma Renée Falconetti que dos décadas después (como nos recuerda Cozarinsky en Boulevards du crépuscule) moriría en la ciudad a la que había llegado como inmigrante-Buenos Aires, donde bien pudo haberse cruzado con un adolescente Raschella. Es la Juana a quien seca las lágrimas, en un gesto que le deforma la cara, el joven monje interpretado por Artaud; hablamos, desde luego, de la escena previa a la entrada en la sala de torturas, cuya maquinaria la cámara de Dreyer nos muestra en ráfagas de una violencia sólo escandida por el rostro de la mártir. En $L a$ casa encontrada ese resto de espanto ineludible, aquí concentrado en la "cabeza rapada", es evidente sobre todo en los dos primeros poemarios, donde aun la escena mítica de la que hablábamos al comienzo adquiere un tono y un ritmo que son los de la época: "ese infierno que se arrastra con mi propia madre mi propio padre mi propio / patio" (104).

En los dos últimos, las anotaciones ceden paso a un lirismo transfigurado por la llegada de lo que se llama "otra juventud" o, con más frecuencia, "vida nueva". Aquí, la extremada tensión presente en Malditos los gallos y Poemas del exterminio es relevada por una voz que no intenta ya evitar la gentileza, palabra que se repite en varios poemas y que, seguramente, hay que leer en sus resonancias dantescas: la gentilissima Beatrice, la gentil balatta mia de la Vita Nuova.

Como toda forma de vida, la vida nueva no es un mero dato de existencia, de simple afirmación o de dichoso arribo a la edad tardía. Aunque la dicha, a la manera de esa "risa dialectal" que celebraba Pasolini en Las cenizas de Gramsci, no esté ausente de La casa encontrada, "nunca es clara la vida nueva, nunca es simple" (251). Es por el contrario el objeto de un trabajo, de una ascesis que va cubriendo los días y las décadas. Sabemos que, desde hace varios años, Raschella escribe dos novelas, además de un libro de poesía. Si consideramos las referencias a la obra juvenil de Dante, donde prosa y verso se mezclaban en la incandescencia autobiográfica y el comentario crítico, podemos vislumbrar algo de la impureza que esos escritos nos deparan. Por lo pronto, se acumulan en los cuadernos de Raschella, desde donde avanzan hacia los lectores con "suprema lentitud". 